
Unexpected Beginnings and Rotated Riffs in Meshuggah's obZen

\author{
Olivia R. Lucas
}

NOTE: The examples for the (text-only) PDF version of this item are available online at: http://www.mtosmt.org/issues/mto.18.24.3/mto.18.24.3.lucas.php

KEYWORDS: rhythm, meter, form, metal, spectrogram, Meshuggah

ABSTRACT: The music of Swedish extreme metal band Meshuggah is known for combining a rigid ${ }_{4}^{4}$-based hypermetrical song structure with riffs having a variety of durational spans. These looping riffs fall in and out of alignment with this background structure, but rarely overcome it, as their cycling is cut off at the end of the hypermetrical segment. Some riffs, however, further complicate this structure by seeming to begin in media res. This article studies three such riffs from the 2008 album $o b Z e n$ as a way of analyzing the larger juxtaposition of rigidly regular quadruple hypermetrical song segments with riffs that struggle-and usually fail-to destabilize those structures. In my analyses, I move between conventional transcriptions and spectrograms, with an eye (and ear) toward questioning what each can tell us about musical events. Finally, with lyrics often centered on the desire for radical freedom or enlightenment, and musical patterns that ritualize the suppression of elements that break the "order" of ${ }_{4}^{4}$, I suggest that Meshuggah's use of rhythm and form explores ideas of freedom and rigid control, liveliness and predictability, with which listeners engage via a variety of embodied listening practices.

Received July 2017

Volume 24, Number 3, September 2018

Copyright $@ 2018$ Society for Music Theory

\title{
Anticipating the Attack
}

May 19, 2012

[1] In a gutted art deco theater in Worcester, MA, metalheads from the entire New England region pack the room, crowding into the pit, shifting impatiently as roadies finish assembling Meshuggah's entirely wireless stage setup. The stage is unusually tidy-no mic stands, no cables, just the drumset, speaker cabinets, monitors, and racks of guitars to either side of the stage.

[2] The venue's background music turns off and the house lights go down. A roar of anticipation rises from the crowd, as hundreds of metal horns gesture frantically toward the stage. I am standing about two-thirds of the way back, on the risers where the venue's stadium seating used to be. Below me, in the pit, something incredible is happening: the impatient jostling and shifting of the crowd has erupted into a full mosh pit before the band has even come onto the stage. A 
physical anacrusis to an anticipated downbeat, the show has begun before the beginning; as the churning mass of listeners hurls itself in violent circles, willing the music to happen, I check that my earplugs are fully in place.

[3] As if in response to the hundreds of screaming, moshing conductors, the band launches its attack: a sonic beating that will last an hour and a half, the stamina and relentlessness of which can only be described in terms of heavy machinery. They do not rile the audience, nor do they gesture or banter; they only assail the crowd with a continuous volley of sound. Each of the five musicians stakes out his spot on stage and roots himself there, a gear in a sonic war machine. The vocalist plants one foot on the monitor in front of him, opens his chest like an opera singer and roars into a wireless handheld mic. Veins stand out along his temples. His timbre is rough, yet incredibly even, a melody-denying pure percussiveness, each consonant precisely placed. Guitar and bass, often doubling each other at the octave, reverberate with their crisp, metallic chug, pummeling the audience with another layer of percussive blasts. Behind them, the drums battle on with impossible speed, every stroke clear and even. Together, these five humans create an inhuman sound, an assault on the ears that beats the body into motion-a headbanging, fist pumping, body-hurling search for an ever-shifting accent scheme. Grooves develop, only to be cut off and supplanted by new ones. All throughout, the lightshow synchronizes with the music's rhythms, so that the patterns of the guitar riffs are driven directly into eyes, ears, and bones. There is no letup, no softening, no lyrical interlude, nothing remotely singable. They show no signs of exhaustion, even as the moshers drip with sweat and are driven to drink water rather than alcohol.

[4] Above me, in the balcony, sit those who come not to mosh but to count. These students of rhythm and meter decipher every pattern, listening for each stroke to be placed accurately. For them, Meshuggah's performance enacts a quieter, subtler battle of fine motor control and mental management of multiple rhythmic layers that fall in and out of alignment. One of them alleged that the band made exactly one mistake that evening (in terms of deviating from the recorded track): a single misplaced sixteenth note. ${ }^{(1)}$ While Meshuggah is hardly the only extreme metal band to write rhythmically complicated music - see, for example, many of the analyses in Osborn 2011their compositional style remains grounded in a sense of propulsion and groove that gives their music a visceral, bodily appeal that both draws listeners into the mosh pit and encourages them to listen closely and decipher the rhythmic patterns. Meshuggah's performances create a musical environment that legitimizes multiple listening strategies; there is pleasure to be found in losing oneself in the mosh pit, as well as in analytic understanding, and Meshuggah's concerts provide a site where these pleasures can collide, interact, and inform each other. The band's ability to create music that is both physically and analytically engaging has enabled Meshuggah to remain a standard of the metal scene for nearly three decades, and has also brought them the (dubious, perhaps) honor of being the first extreme metal band to be taken under the wing of academic music theory and its analytical tools (See Pieslak 2007).

\section{Introduction}

[5] Meshuggah is an extreme metal band from Sweden, ${ }^{(2)}$ named after the Yiddish word for "crazy" or "nonsense."(3) They formed in 1987, released their first album in 1991, and in 2014 they completed a $25^{\text {th }}$ anniversary world tour; their most recent album was released in 2016 . Today, they remain a well-established element of the extreme metal world. Respected by metalheads for their commitment to virtuosic, aggressive playing, Meshuggah has also developed a following amongst listeners interested in rhythmic intricacy, including among people who may not be interested in metal more generally. ${ }^{(4)}$ Over the course of their career, Meshuggah's music has explored a variety of stylistic directions. This article focuses exclusively on examples from their 2008 release $o b Z e n$, but many of this album's traits are common to the musical style they have developed since 2002's Nothing.

[6] This article employs close readings of moments in Meshuggah's music in which riffs seem to begin in media res, and harnesses them toward scrutiny of the larger juxtaposition of rigidly regular quadruple hypermetrical song segments with riffs that struggle-and usually fail-to destabilize those very structures. Toying with the internal rhythmic structures of riffs so that they sound as if they begin in the middle helps illuminate the significant form-generating role of the junctures 
between song segments. Furthermore, it is these junctures - where an errant riff is subdued by hypermetrical regularity - that provide a site for interrogating human ambivalence with regard to novelty, repetition, the comfort of reliable structures, and the excitement of pushing against those structures. How listeners interacted with Meshuggah's music at the concert-by counting in the balcony and moshing in the pit, for example-highlights the multiple surface manifestations of human engagement with musical rhythm and form and the embodied pleasures of encountering rhythmic conflict. Finally, the lyrics the vocalist screams offer oblique reflections on the musical structures they inhabit. Particularly, their frequent emphasis on de-tangling systems built on deception, and alternatively, on being trapped in or freeing oneself from these systems dovetails succinctly with the use of musical patterns that ritualize the suppression of elements that break the "order" of a ${ }_{4}^{4}$-based structure.

[7] In the sections that follow, I first introduce important aspects of Meshuggah's rhythmic style as heard on obZen and clarify how my approach both draws on and differs from previous analyses of this music. I then present the idea of riffs that seem to begin in media res, before proceeding with four analytical examples. Subsequently, these analyses fuel a discussion about listening to rhythm and form in this music, filtered through the listening practices observed at the concert described above.

\section{Hearing the Rhythms of obZen}

[8] When listening to obZen, I notice that the sound lurches and rolls, grooves and hiccups, unpredictable yet paradoxically organized - a controlled tumult of drums, guitars, and screams. Pitch content is often minimal, seemingly arbitrary and rarely melodic in any conventional sense. Jagged patterns emerge, stop short, and begin again, continually interrupting the familiar and the predictable. Round pegs stuck into square holes, these riffs are simultaneously even and odd, regular and irregular. These feelings of simultaneous conflict and stability are wrought through the band's primary compositional technique of creating metrically even, large-scale musical structures and filling them with local patterns having conflicting durational spans. Typically, Meshuggah builds songs in segments of eight, sixteen, or thirty-two measures of ${ }_{4}^{4}$. I use "song segment" to refer to these larger time-spans by which Meshuggah organizes their music, as their songs tend not to have identifiable verses, choruses, etc., though most feature a guitar solo. Songs generally follow a pattern of segments without vocals alternating with segments with vocals (similar to Osborn's (2011, [27]) "independent verses"). They do repeat riffs, but rarely in a consistently alternating pattern. Furthermore, a song could have a dozen different riffs, with one or two of them repeating at some point. In short, individual song segments do not typically indicate to listeners "where" in the song they are.

[9] Within these song segments, riffs having a wide variety of durations - such as $9 \downarrow, 7 \downarrow, 25 \bullet$, etc. - play on loop, repeating as they fall in and out of phase with the ${ }_{4}^{4}$ background structure. In many cases, the ${ }_{4}^{4}$ meter remains explicitly articulated, often by means of a steady quarter-note pulse in the cymbals, a backbeat on the snare, or by means of whole notes in the lead guitar marking the ${ }_{4}^{4}$ downbeats. When the looping riff reaches the edge of the eight, sixteen, twenty-four, or thirty-two measure song segment, it is typically cut off wherever it happens to be in its process, and a new riff is initiated on the downbeat of the next segment. ${ }^{(5)}$ The combination of the articulation of phasing rhythmic patterns, the lack of transition between riffs, and the looping of each riff results in rhythmic sensations of lurching, rolling, and stopping short, yet with a lurking continuity as if some invisible ordering force were in control. ${ }^{(6)}$

[10] Despite the clarity that their definitions offer, I am hesitant to designate Meshuggah's music as "polyrhythmic" (following Pieslak 2007, 221), "rhythmically dissonant," or "metrically dissonant" in a strict fashion. ${ }^{(7)}$ Whether the music is heard as polyrhythmic, rhythmically or metrically dissonant, or simply as some kind of "weird 4 " depends on the listener, the song, and sometimes even the segment of the song, and I am attentive to and interested in varied ways of hearing this music. To my mind there are (at least) two ways of "getting" this music. Someone who is following the ${ }_{4}^{4}$ in all its weirdness is enjoying it differently, but no less fully, than a listener who parses the music polyrhythmically. ${ }^{(8)}$ 
[11] Even among the examples presented here, the aural clarity and relative strength of the various layers of musical activity varies widely. While it is true that the pulses of the ${ }_{4}^{4}$ meter that form the hypermetrical structure are, in most cases, explicitly articulated somewhere in the texture, the perceptual salience of this articulation relative to other patterns can shift over the course of a song, and in some cases seems deliberately hidden away. In their song "Bleed," for example, the ${ }_{4}^{4}$ pulses are loudly and cleanly articulated in the cymbals for the first 1:25 of the song (Example 1a). At this point, the cymbals begin to strike every eighth-note (rather than every quarter) resulting in a blurry wash of sound, while the kick drum begins to pop through more loudly as it articulates the 3 pattern in the guitars. At 1:40, the cymbals also begin following the new pattern $\left(22 D^{\circ}\right)$ articulated in the drums and guitars, rendering the vocals the textural layer most expressive of ${ }_{4}^{4}$ until 1:58, when the lead guitar steps in to articulate the ${ }_{4}^{4}$ downbeats (Example 1b). The music rarely leaves listeners hanging without an audible ${ }_{4}^{4}$ pulse for long, but the fact that the relative salience of this layer ebbs and flows suggests that while the ${ }_{4}^{4}$ based hypermetrical structure remains theoretically present, on a moment-to-moment basis, its primacy can be destabilized. Listeners' ability to hold onto the ${ }_{4}^{4}$ pulse when it is not explicitly articulated will necessarily vary. Even when the ${ }_{4}^{4}$ pulse is explicitly sounded, listeners might choose to attend primarily to other layers. Therefore, while Meshuggah's compositional technique often comprises what is best described as rhythmic dissonance, I submit that other designations remain possible.

[12] In concentrating on understanding rhythmic events as they unfold in Meshuggah's music, I additionally take on Christopher Hasty's (1997, ix) exhortation that theorists deal with "real potentiality, indeterminacy, and novelty" in the process of untangling the temporality of musical events. My analyses are grounded in Hasty's theory of meter as "projective process," which emphasizes the importance of heard internal relationships between durations that unfold and develop while listening (ix-x). ${ }^{(9)}$ For Hasty, the perception of metrical rhythms in music is based on the experience and projection of durational spans as they form into patterns of strong and weak beats. A weak or unaccented beat is the result of a prolongation of the mensural potential of an earlier beginning: "if the earlier beginning is still 'present' and active-this new beginning will be unaccented and 'not-beginning' in relation to the larger event that has already begun and continues to be in the process of becoming" (104). The emergence of a sense of strong and weak occurs not only on a note-by-note level, but also at the level of groups of notes, phrases, and even in the context of the entire piece (114-15). The durational relationships that emerge and form these hierarchies are malleable and subject to change as later events continue to influence their perception. My analysis of these riffs rests primarily at the level of "groups of notes," examining how they hang together to create a clear rhythmic profile with a distinct beginning, middle, and ending. While I do not follow Hasty's method of analysis exactly, I do strive to use a style of moment-by-moment analysis derived from his approach to metrical forming that allows for documentation of how a "beginning" could become a "middle" and vice versa. This style of analysis relies on rhythmic intuition that is emergent in listening; the importance of close listening for understanding these analyses cannot be overstated. In keeping with Hasty's approach, the analyses below describe my (particular, individual) hearing of musical events, but I believe other listeners can share these hearings.

\section{Beginning in the Middle: The Temporality of Rhythmic Re-orientation}

[13] The rhythmic features described above are common to a great deal of Meshuggah's music, but $o b Z e n$ features a unique twist on these procedures, in which the phasing of the riffs is sometimes complicated by the pattern of the riff seeming to "begin in the middle," usually due to features of its attack and accent patterns. Rhythmic groupings in Meshuggah's music arise primarily through attack patterns and their accompanying accents. The tendency toward crisp timbres and clear attacks across all instruments, along with the non-melodic use of pitch, gives the music a percussive quality that foregrounds these attack patterns. ${ }^{(10)}$ Dynamic accents, slides, and bends are used to further shape rhythmic gestures. Meshuggah often shapes riffs by means of durational accents, with a long duration delimiting the end of a riff. ${ }^{(11)}$ Contour and registral accents (pitches that stand out because they are higher or lower than the surrounding ones) often help shape the 
riff's perceived attack points into a clear rhythmic gesture, sometimes in conjunction with dynamic accents. ${ }^{(12)}$

[14] The musical devices Meshuggah uses to shape their riffs are not unique in and of themselves; what is interesting from an analytic standpoint is the use of these devices to bring about temporal re-organization. In some cases, the temporal beginning of a riff is not aligned with the rhythmic gesture of "beginning."(13) In other words, in the process of listening to a song segment, the sense of where the repeating riff begins and ends changes, resulting in a retroactive sense that the riff "began in the middle." I designate what is heard first as the riff's "temporal beginning," and what sounds like the beginning of the riff as the "rhythmic beginning." Following a counterexample demonstrating alignment of temporal and rhythmic beginning, I analyze three examples of riffs that begin in media res, combining attack-point analysis with comparison between the rhythmic data provided by spectrogram analysis and data provided by conventional transcription, to examine how attack-points and accents re-shape the sense of a riff's beginning and ending points.

[15] In the analyses that follow, I make use of both conventional transcriptions and spectrogram analysis, with an eye (and ear) toward questioning what each conveys about musical events. I find that with Meshuggah's music, spectrograms open up a revealing perspective on rhythmic structures, particularly with regard to visualizing event onsets, groupings, and repetitions of groupings. Using spectrograms in this way focuses observations on readily apparent clusters and gaps of visual material that indicate rhythmic patterns and does not require specialized knowledge of spectral analysis.

\section{"Lethargica"}

[16] A clear example of alignment between temporal and rhythmic beginnings of a riff can be found in the opening of the song "Lethargica." The guitar riff for mm. 1-17 is shown in Example $2^{(14)}$ As Example 2 shows, the opening riff of this song has a total duration of $23 \downarrow$, which can be broken into four shorter groupings of $5 \downarrow+6 \downarrow+6 \downarrow+6 \downarrow$. I find that the groupings that comprise this riff are particularly intuitive, with pairs of segments relating to each other in a "question and answer" manner loosely reminiscent of antecedent and consequent phrases in a period; the subsegments of the riff follow a roughly $A B A^{\prime} B^{\prime}$ pattern. Because the groupings are so coherent, a strong sense of rhythmic expectation develops as the riff loops over the sixteen-measure song segment.

[17] Within the sixteen-measure song segment, the full 23 of the riff will repeat two full times, and continue through eighteen beats of a third repetition before hitting the boundary of the song segment; at $\mathrm{m} .17$, the vocals enter, and the guitars change from the opening riff to a chugging tritone power chord pattern. When the riff reaches the end of $\mathrm{m} .16$, it is just beginning the fourth segment of the 23-beat riff $\left(B^{\prime}\right)$; this abruptly becomes the power-chord pattern of the next song segment at the downbeat of $\mathrm{m}$. 17. This cutting off of a riff in progress, unexpectedly halting its momentum and transferring it to the next pattern is what generates the typical lurching sensation that accompanies listening to a Meshuggah song - a carefully calculated buildup and denial of rhythmic expectation. The location of the 23 - pattern's beginning is clear; its temporal placement aligns with its rhythmic momentum.

[18] The following song segments, with their rotated riffs, provide listeners with novel and distinctive challenges. The process of having to mentally re-orient the riff while also untangling its durational pattern weakens the sense for where song segment boundaries should fall. I examine the factors that help to create these distinctive riffs, how they evolve over the course of their song segment, and what effect they have on the ending of their song segment and the movement into the next one.

\section{"Pineal Gland Optics"}

[19] The opening guitar riff of "Pineal Gland Optics," in combination with the patterns of the drums and lead guitar, showcases this process of beginning in the middle. The song's title refers to the pineal gland, a small endocrine gland shaped like a pinecone found in the brains of vertebrates. 
It produces melatonin and was viewed by Descartes as "the principal seat of the soul" (Lokhorst 2015), and today remains connected to the theosophic concept of the third eye. It is primarily to this latter understanding that Meshuggah refers in the lyrics to this song, which are concerned with mystical visions of a deeper reality; I consider these lyrics later. The opening segment of this song features multiple pitch and rhythmic patterns cycling and falling in and out of alignment with each other. Below, I present each pattern separately before showing the composite. Example 3 shows the eight-attack pitch pattern used in the riff played by the rhythm guitar, a half-step oscillation around $\mathrm{A}$ in the upper voice and $\mathrm{Ab}$ in the lower voice. Example 4 shows the rhythmic pattern used in the riff, which has a length of 14 attacks and a total duration of 12. Example 5 shows the pitch pattern and rhythmic attack pattern as they are combined into the rhythm guitar part of the opening segment of the song. Over the course of the sixteen-measure song segment, the 8-attack pitch pattern and 14-attack rhythmic pattern cycle against each other, re-aligning only after 56 attack points (at the downbeats of $\mathrm{m} .7$ and m. 13).

[20] Several features of this riff result in a pitch pattern that is largely subsumed by the rhythmic pattern. At a tempo of $\downarrow=95$, the sixteenth and eighth note leaping of octaves and $9^{\text {th }} \mathrm{s}$ is sufficiently fast as to sound more or less erratic. ${ }^{(15)}$ Notated, the pitches seem to visually separate into an upper and lower voice, but for me, with the association between pitch and duration severed, a sense of compound melody never develops aurally. These factors, in combination with Meshuggah's typically low-register, percussive guitar tone, contribute to my hearing of this guitar riff as primarily oriented around its rhythmic profile.

[21] The riff's rhythmic structure, though initially sounding quite erratic, is strengthened by the presence of one longer duration - the dotted eighth note that falls on rhythmic attack point 12, as shown in Example 6. Given the otherwise unstable configuration of this riff, the dotted eighth near the end of the riff, as the longest duration in the rhythmic pattern, comes to have an important role in shaping the riff's perceived orientation.

[22] Ostensibly, this guitar pattern articulates a riff with a duration of $6 \cdot$; however, any perception of a six-beat pattern in the case of this riff derives primarily from the sense of the entire rhythmic pattern repeating. Otherwise, the "sixness" of the riff is considerably obscured by the lack of a duple division after the third beat, the uneven pattern of sixteenths and eighths, as well as by the isorhythm. To my ear, attack points 11 and 12 (ㄷ. .), along with other factors discussed below, largely drive perception of rhythmic organization in this song segment.

[23] Example 7 shows the rhythm guitars in their broader context of the opening sixteen measures of "Pineal Gland Optics." (16) The riff shown in Example 5 receives rhythmic support from the bass drum, as shown in Example 7; the drum does not sound with every guitar attack, but never contradicts the guitar pattern. The hi-hat foot pedal fills in the drums largely at the sixteenth-note level. The snare drum strikes the second half of every beat (arguably articulating ${ }_{4}^{4}$ ). Above these cyclic patterns hangs a solitary tone in the lead guitar, registrally separated from the rest of the music and slowly oscillating between $C \#$ and D every eight beats (or two measures of ${ }_{4}^{4}$ ). Cymbal strikes reinforce the temporal beginning of the riff only when it aligns with a change of pitch in the lead guitar (see mm. 1, 7, and 13); otherwise, the temporal beginning of the riff aligns with a sixteenth rest in the cymbal (see mm. 2, 4, 5, 8, 10,11,14, and 16). The cymbals always sound in support of the f. figure that appears on beat five of the riff, appearing for the first time at the downbeat of $\mathrm{m}$. 2. With the exception of sounding/not sounding based on the context of the riff's temporal beginning, the cymbals play a consistently repeating pattern, like the other instruments.

[24] The red boxes in Example 7 depict the alignment of the riff's temporal beginning with the change of pitch in the lead guitar, which necessarily means that it also aligns with the downbeat of $\mathrm{a}_{4}^{4}$ measure. These moments ( $\mathrm{mm} .7$ and 13) mark the point when the competing cycles converge for an instant before continuing on their paths. Typically, the convergence of the rhythmic cycles gives me a feeling of being back at the beginning - a brief flash of rhythmic stability. In this case, however, the weaknesses of the various patterns result in a feeling of ongoing rhythmic instability and point to other moments in the passage as rhythmic signposts. 
[25] Using a spectrogram, this passage can be considered from a more aurally focused perspective, which suggests evidence for alternative rhythmic groupings, based on the blue boxes in Example 7. Example 8 shows a spectrogram of the first eleven seconds of the song.

[26] The most salient aspects of this excerpt are the lead guitar and kick drum. These elements make clear marks on the spectrogram: long horizontal lines in the case of the lead guitar, and short, vertical ticks in the case of the kick drum. The high-register lead guitar oscillation between C\# and $\mathrm{D}$ A every eight beats provides an anchoring architecture that slips in and out of phase with the other patterns. While many of Meshuggah's songs use a similar oscillating pattern as a metric anchor, the relatively slow pulse of "Pineal Gland Optics" renders the duration of the eight-beat span between each attack uncomfortably long for me to use as a rhythmic reckoning tool. Nevertheless, each pitch change initiates a strong sense of downbeat which tends to conflict with the pulse organization generated by the other layers of activity.

[27] Zooming in along the bottom of the spectrogram to look at the black marks of the kick drum hits, visual grouping begins to emerge more clearly (Example 9). The gaps between these groups of kick drum hits are longer than any gap within the groups. Comparing this image with the transcription, these large gaps correspond to the $\int$. figure in the guitars near the end of the 6 . pattern. As the dotted eighth is the longest duration in the riff, this moment suspends activity long enough to stand out, tending to re-orient the rest of the riff around itself. ${ }^{(17)}$ This moment, which initially seems to be the fifth and part of the sixth beats of the riff, mutates to sound like its beginning due to the strong durational accent.

[28] The kick drum marks in Example 9 provide visual cues of this "beginning in the middle." A close examination reveals that the first group of kick drum marks is slightly shorter than the subsequent groups, and the internal spacing of the marks within the group differs. It is this gap between the groupings which, to my ear, ends up sounding like the beginning of the riff, due to the D. figure in the rhythm guitars and the way the cymbal pattern is configured.

[29] This reinterpretation of the rhythmic beginning of the riff has implications for the moments of alignment with the eight-beat cycle imposed by the lead guitar. The moments when the $\curvearrowleft$. gesture aligns with the shifting of the lead guitar's pitch (see mm. 5 and 11 in Example 7) form the passage's clearest rhythmic anchoring points and sense of downbeat. These moments can also be seen in a spectrogram; the first instance of this is shown in Example 10. This alignment of the big gap/ $/$. gesture with the pitch oscillation in the lead guitar occurs twice over the course of the song's sixteen-measure introduction, in mm. 5 and 11.

[30] From the perspective of actively listening to the music unfold, hearing the riff as beginning, ending and then beginning again with the 5 rhythm (i.e. its temporal beginning) becomes increasingly difficult for me, especially after m. 5 when the. . gesture aligns with the lead guitar oscillation. (Here, particularly, the lead guitar's return to the initial C\# pitch adds to the feeling of "home.") When listening, I instinctively re-orient my thinking about the riff such that I hear it beginning with the. . gesture, and understand the song as having begun with the riff in the middle of its process.

[31] Typically, Meshuggah's music is not so deceptive with regard to the beginnings and endings of musical segments; as exemplified by the "Lethargica" excerpt, what is heard first is generally "the beginning," recognizable when it comes again after the riff's "ending," and then cut off midstride whenever the next song section begins. This cutting off of riffs mid-stride when they reach the edge of their eight- or sixteen-measure song segment is what creates the familiar lurching sensation, as a "middle" unexpectedly collides with a new "beginning." In the case of "Pineal Gland Optics," however, the band seems to have taken nearly the opposite strategy. Example 11 shows via a spectrogram the moment when the riff ends, the lead guitar drops out, and the vocals enter, beginning the next song segment.

[32] As it happens, the downbeat of m. 17 is exactly where the $\curvearrowleft$. would appear if the riff were to continue unchanged. And in fact, it does appear here: the stabilizing $\int$. figure ushers in the next song section, spectacularly performing its "beginning" function. Here, what initially confused the 
beginning of the riff clarifies the transition into the next song segment. Meshuggah thus reverses an element of their conventional compositional process, temporally beginning a riff at what turns out to be mid-stride, while concluding it in the most logical place. ${ }^{(18)}$

[33] Aurally, the reinterpretation of middle as beginning is relatively clear. On the one hand, this type of "beginning in the middle" is atypical of Meshuggah's style, and is in some respects more complicated than their usual tactic, requiring retroactive rhythmic understanding. On the other hand, the way the $\neg$. figure is placed so that it falls right onto the opening of the next song segments demonstrates how the grouping structure of a riff can influence the perception of formal boundaries in this music.

[34] Following the first verse, there is an instrumental interlude in $\mathrm{mm}$. 25-32, which returns to the initial riff in quasi-inversion, beginning (temporally and rhythmically) on the $\int$. rhythmic figure now as an upward rather than downward gesture. The pitches hover around $G$ in the upper voice and $A b$ in the lower voice. This riff repeats a full five times and then is cut off mid-stride after two beats of the sixth repetition. Here, then, Meshuggah uses the riff in a manner that is more typical of their compositional style, reinforcing the idea that the riff's initial presentation began "in the middle."

[35] The kind of careful aural attention that hears "Pineal Gland Optics" begin in media res relies on hearing the pattern change as it unfolds in time. The rotation of the opening riff has not only a local effect on my hearing of the segment, but also ricochets across its boundary as its rhythmic beginning introduces the next riff. While this riff follows the formal norms of the style-it is cut off when the downbeat of $\mathrm{m}$. 17 arrives - it also surreptitiously weakens this rigid formal boundary, blurring it without changing its structure.

\section{"Pravus"}

[36] A similar rhythmic situation unfolds in the song "Pravus," this time in a short 8-measure segment from the middle of the song (1:41-1:55). Here, the pitch and rhythm patterns are both 15 attacks long, resulting in a more straightforward riff. Example 12 shows the rhythmic attack pattern for the rhythm guitars, which has a duration of 9.5 . The top line shows the pattern beginning with the temporal beginning, while the bottom line has rotated the pattern to show the rhythmic beginning that I hear, shifted to show where it aligns with the initial presentation of the pattern. Example 13 shows these rhythmic patterns combined with pitch. Note that the pitches the eighth notes fall on are at least a major $6^{\text {th }}$ higher than either adjacent pitch. These higher pitches and longer durations together create the rhythmic backbone of the pattern. ${ }^{(19)}$ Example 14 shows the first three measures of this segment in context. The rhythmic situation here is simpler than the one at the opening of "Pineal Gland Optics," as there are fewer parts to align; here, there is no lead guitar figure, the cymbals keep a steady quarter note pulse, and the snare and kick drum rhythmically duplicate the guitar pattern.

[37] The guitars articulate a pattern with a duration of 9. that is shaped primarily by the As and $G \#$ in the upper voice. Emphasized by snare hits, these pitches hang together in a unified "stream" of A-G\#-A neighbor figures, with a temporal gap between each iteration. That this temporal gap first appears near the beginning of the song segment plays an important role in creating a sense that the riff began in the middle. The temporal gap between adjacent As, as it is longer than the temporal gaps between the $A$ and $G \#$ or the $G \#$ and the $A$, further causes each iteration of the A-G\#-A pattern to cohere into a unified musical figure. Each iteration of this pattern is then separated by this longer temporal gap, setting up the experience of a looped riff. That this longer temporal gap comes near the beginning of the song segment plays an important role in creating a sense that the riff began in the middle.

[38] The red bracket in Example 14 shows the 9. pattern as it would be counted off from the temporal beginning of the song segment. As the pattern repeats, this orientation becomes increasingly difficult to hear due to its unaccented beginning, and the subsequent three eighth notes worth of "dead space." The purple bracket in Example 14 shows the rhythmic unit into 
which the A-G\#-A neighbor figure reorients the pattern. With this orientation, the last three eighth notes worth sound like a space that separates iterations of the neighbor figure.

[39] What is particularly interesting about this example is the clarity with which this riff's rhythmic beginning can be deduced from a spectrogram of the song segment, shown in Example 15.

Zooming in on the beginning of the passage in Example 16, the drumming pattern emerges more clearly. This example shows the riff emerging out of the first verse, with the roar of the word "dry" running over its beginning. Once the riff is underway, the snare hits make clear vertical lines ascending from the end of each group of double bass strikes. These double bass rolls fill the time between each of the "structural" guitar pitches (the circled As and G\#s in the transcription, Example 14), whose onsets align with the snare strikes. Example 16 also shows "columns" - the gaps of whiter space where the kick drums have paused to allow the guitar to sound-that emerge and form groups. Each group is composed of three columns, the first one slightly further away from the subsequent two. Each group of columns is separated by a slightly larger distance than that between the first and second column of each group.

[40] At the bottom of the spectrogram, the kick drum hits provide clarity about timing in this passage. Each kick drum strike is evenly, yet tightly spaced; each group is a short burst of double bass activity, with each tick mark corresponding to the sixteenth-note subdivision shown in the transcription (Example 14). Counting out each kick drum strike in the spectrogram reveals a pattern with a duration of nine eighth notes, and from this perspective, it makes sense visually to use the groups of columns as guideposts for the beginning and ending of that pattern.

[41] Looking toward the left of the spectrogram in Example 16, around the 101 second mark, the lowermost portion of the very first column appears beneath the vocals. This column marks the temporal beginning of the song segment. The spectrogram shows that the first column is six bass drum strikes away from the next column, meaning that the passage essentially begins with the functional ending of the riff-its last half note's worth, most of which is the "dead space" between iterations of the neighbor figure. In other words, the visual groupings that emerge in the spectrogram suggest a riff that begins in media res. With the way the vocals hang over the beginning of this passage, it sounds to me as if the riff has been going on for a while underneath some other music, and finally happens to surface for a brief while.

[42] Finally, this orientation of the riff makes for a more rhythmically convincing transition into the next song segment (which in this case is a two-measure "fill" before a new riff and the re-entry of the vocals). Example 17 zooms in on the ending of the song segment. Example 18 provides a transcription of the last three measures of the song segment and the beginning of the next.

[43] After the last full statement of the riff, the first 5.7 are heard again; just when the third and last of the accented guitar tones should sound, the beginning of the next song segment cuts the repetition short. The downbeat of the next song section falls at the moment when rhythmic expectation is highest in the riff. The arrival instead on the "wrong" note and a new rhythmic figure feels different than the typical lurch that arises from a riff being cut off mid-stride in the transition to the next song segment; there is a stronger feeling of denied expectation. Unlike the way the accented moment of the "Pineal Gland Optics" riff ushers in the beginning of the verse, here, a strong expectation of such a continuation is created, but then evaded. Whereas the transition between segments one and two of "Pineal Gland Optics" tugs at the rigidity of the segment barrier by blurring beginning and ending, here the boundary is highlighted and made more obvious by the rotation of the riff.

\section{"Pravus," Part Two}

[44] Later in the song "Pravus," (2:31-3:00), there is another instance of a riff that begins in the middle, with yet another treatment of the moment when one riff meets the next after sixteen measures. Example 19 shows the rhythmic attack pattern for the rhythm guitars, which has a duration of 7 . The top line shows the pattern beginning with the temporal beginning, while the bottom line has rotated the pattern to show the rhythmic beginning that I hear, and shifted it to show where it aligns with the initial presentation of the pattern. Example 20 shows these rhythmic 
patterns combined with pitch. In this pattern, lower pitches and longer durations shape the rhythmic structure. Example 21 shows a transcription of the first three measures of this song segment.

[45] Surrounding the rhythm guitar pattern introduced in Examples 19 and 20, a steady quarter note pulse is kept by the cymbals, as well the drum pattern of a snare hit followed by a double bass roll. Like "Pineal Gland Optics," this song segment has a slow lead guitar part in a higher register. In this example, however, the lead guitar drifts along more loosely with the riff, demarcating units of approximately eight beats, sometimes an eighth note more or less. ${ }^{(20)}$ In the context of Meshuggah's style, this $7 \cdot$ pattern is relatively simple, with minimal rhythmic conflict.

[46] As with the "Pineal Gland Optics" example, this passage is rhythmically oriented primarily by a long duration of low pitch, in this case a dotted quarter note on a low $\mathrm{F}$ that sounds like the ending of the riff. What is particularly interesting about this pattern, however, is the eighth note that sounds halfway through m. 2 of Example 21. Measure 1 contains a statement of what seems like a riff with a duration of 3 . The remainder of $\mathrm{m}$. 1 , up until the eighth note in $\mathrm{m}$. 2, sounds like a repetition that extends the pattern by one beat. The eighth note causes a "catching" feeling, that at first listen sounds to me like an ending durational accent. The continuation, however, until the dotted quarter note comes during the sixth beat, demonstrates that both initial projections were incorrect. With repetition, this eighth note in the third beat becomes the marker of a $3+4$ subdivision of the $7 \cdot$ riff.

[47] This particular song segment is sixteen measures long and is divided in half with the entire pattern starting over at the downbeat of m. 9. Example 22 shows a spectrogram of this song segment, with the mid-point circled; there are four full statements of the 7 riff on either side of the midpoint, which can be easily identified by the drumming pattern. In the spectrogram, clusters of kick drum action are separated by short and long horizontal marks representing the eighth note "catch" and the dotted quarter note that ends the riff, respectively. The short and long marks alternate, until the midpoint of the riff, when the spectrogram shows two long durations too close together, with no intervening short "catch." This apparent glitch in the pattern occurs because, at the ninth measure of the song segment, the entire process begins again with the "beginning in the middle" - there is a starting over at the temporal beginning. Example 23 shows a transcription of $\mathrm{mm}$. 8-10 of this passage.

[48] At the end of m. 8, the first quarter note's worth $\left(4{ }^{\prime}\right)$ of the riff is played, before being cut off mid-stride at the barline. In re-starting the riff, they restart with the temporal beginning, repeating the process of beginning in the middle. The lead guitar's re-launch of its pitch pattern at the beginning of $\mathrm{m} .9$ further emphasizes the repetition. What makes this moment more aurally complex is the fact that the beginning of the riff as played at the end of $\mathrm{m}$. 8 joins seamlessly with the riff segment played at the beginning of m. 9; aurally, it is simply the first 3 of the $3+4$ that makes up the 7 riff until what should be the eighth note "catch" lasts too long. When listening, it is only retrospectively - after the "catch" lasts too long and the next full iteration of the 7 riff has gone by - that we can know there has been a re-statement of the temporal beginning.

[49] At the end of the song segment, the transition from the sixteenth measure into the seventeenth plays a similar trick; Example 24 shows a transcription of the last two measures of the riff and the first of the next song segment. The new riff that begins the next song segment is a call-and-response pattern between a jagged figure ending with a long duration similar to the previous motive, alternating with rising sixteenths doubled at the octave. The last full statement of the 7 pattern ends in $\mathrm{m}$. 16, beginning again in the last beat of the measure. At the downbeat of $\mathrm{m}$. 17, it is cut off mid-stride and the lead guitar drops out, but the gesture that begins the new riff continues the same rhythmic pattern, albeit with different pitches. The long low F in beats $2-3$ of $\mathrm{m} .17$ is, however, on the "right" pitch, and is held for the correct dotted quarter note duration. The octaves that begin at the end of $\mathrm{m}$. 17 firmly demonstrate that a new riff has begun. Though the change in pitch content signals that a new pattern is beginning, the new riff begins with the same rhythm, and therefore a clear understanding of the song section's border comes retrospectively for me, only once the rising octaves signal that there is, in fact, a new riff. 
[50] In this instance, Meshuggah has blended the ending of one song segment with the beginning of the next; the change in pitch makes the border aurally distinguishable, but the similarity of the rhythmic pattern lessens the lurch that is typical of movements between song segments in their music. ${ }^{(21)}$ Here, again, the rotation of a riff has effects extending beyond the local segment, shaping the interpretation of the formal boundary that follows, as if gently querying its rigidity.

\section{Discussion}

[51] In each of the four examples analyzed above, the rhythmic surface of the guitar riff meets the edge of its formal boundary in a slightly different way, though in all four instances I hear the riff yield to the boundary's structuring role. The opening of "Lethargica" hits the song segment wall abruptly; the rhythmic surface immediately transforms into something else, both rhythmically and texturally. "Pineal Gland Optics," on the other hand, seems to end its opening segment where it should, the functional end of the riff converging with the seam of the hypermetrical structure. In the first "Pravus" example, a denial of expectation occurs as the segment ends when anticipation is highest in the riff. And later in that song, the ending of one riff blends rhythmically with the beginning of the next, momentarily hiding a typically audible seam. It is the subtleties of these moments that render a description like "regular quadruple hypermetric structure + rhythmically varied surface within that structure" incomplete as an explanation of form in Meshuggah's music; there is a buoyant push and pull between these elements that suffuses the music with a rhythmic ambivalence that is brought to life in the behaviors of the listeners at the concert, as they respond to this push and pull in their moshing and their counting. ${ }^{(22)}$

[52] In the context of a music culture that values transgressive displays of aggression, Meshuggah's use of looping riffs that are consistently cut off by a rigid ${ }_{4}^{4}$-based hypermetric structure enacts a ritual of freedom and control that has long been identified as a core component of metal music's aesthetic, first described in Robert Walser's 1993 book Running with the Devil: Power Gender and Madness in Heavy Metal Music. As Walser writes:

Musically, a dialectic is often set up between the potentially oppressive power of bass, drums and rhythm guitar, and the liberating, empowering vehicle of the guitar solo or the resistance of the voice. The feeling of freedom created by the freedom of motion of the guitar solos and fills can be at various times supported, defended or threatened by the physical power of the bass and the violence of the drums. The latter rigidly organize and control time; the guitar escapes with flashy runs and other arrhythmic gestures. The solo positions the listener: he or she can identify with the controlling power without feeling threatened, because the solo can transcend anything. (53-

54)

Though Walser's context for this claim is the "freedom" of wild guitar solos arising out of the "control" of the rhythm section, I believe Meshuggah's riff/structure struggle, which is almost always resolved in favor of the structure, proceeds from this same artistic instinct. With song lyrics often centered on the desire for or achievement of radical freedom from invasive, oppressive, and deceptive systems, and musical patterns that ritualize the suppression of elements that break the

"order" of ${ }_{4}^{4}$, it seems the formal organization of Meshuggah's music explores ideas of freedom and rigid control, liveliness, and predictability. Just as their manipulations of rhythm exhibit competing realities - one of which exerts control over the other - the texts that Jens Kidman screams often deal with competing realities, and the struggle to either escape a malicious one or discover what is truly real. Take, for example, these lines from "Pineal Gland Optics:"

Unbound this new vision, optical regenesis

Threatening, so complete in beautiful deformity

$[\ldots]$ 
Cast off - the concealing veil, the rational cloak of doubt

Torn off - the restraints, the blinded's shackles

Burned away - the agony, the fear, the grief

A new set of eyes cleansed by a new belief. ${ }^{(23)}$

Here, the text centers on the narrator's discovery of a perceived truth, in an experience akin to receiving new eyes. The event is life-altering, and brings the subject a heretofore unknown freedom, a reality that is "complete in beautiful deformity." This lyric remarks on the compatibility of deformity and aesthetic pleasure. Joseph Straus' $(2006,175)$ study of concepts of disability in music theory notes that, "musical works often benefit aesthetically from the presence of formal deformations and abnormalities, tonal problems with their attendant imbalance and unrest, and dissonances requiring normalization." I believe that Meshuggah's treatment of competing rhythmic strata qualifies for consideration through this lens. The riff struggles to deform the structure, and the structure normalizes the riff, forming boundaries for its excursions and bringing to mind the normative social forces applied to human bodies in everyday life. While Meshuggah's music does not encode disability per se, analyses of it that employ metaphors involving (a)symmetries and formal "containers" whose boundaries are at risk of perforation, draw on a history of analytical devices that are "unpleasant in [their] unexamined assumption that our bodies and our bodily experiences are all the same" $(124) ;(24)$ the varied expressions of embodied rhythmic engagement by the moshers and nerds at the concert highlight the absurdity of this assumption. Meshuggah's use of rotated riffs that threaten the stability of the larger structure reflects on the liveliness and aesthetic pleasure of difference, as well as the competing comfort of regularity and predictability, in this case perfectly represented by ${ }_{4}^{4}$, with all its attendant history and significance for Western music. "Pineal Gland Optics" and "Pravus" (whose lyrics contemplate the inescapable inevitability of suffering, violence and death: "By the poisoned nails of history stung. . .the blades of hurt inexhaustibly swung"), by playing with the temporal signification of rhythmic grouping, offer yet another way of hearing the encounter between norm and aberration, conformity and rebellion.

\section{Conclusion}

[53] Meshuggah's music offers a great deal to the world of musical analysis, particularly in terms of musical parameters that have long received the respect and attention of music theorists: a coherent but evolving compositional style with a distinctive way of handling local and large-scale rhythmic and metrical patterns, and a unique management of motivic development. With a rhythmic surface that does not easily and immediately yield to interpretation, it comes as no surprise that

Meshuggah is the first extreme metal band to inspire a Spectrum article (Pieslak 2007), and I suspect it will only be a matter of time until there is a recognizable, if small, school of "Meshuggah analysis," like those devoted to other composers and bands. In this article, I have focused on one aspect of their music, dissecting how in some instances, interpretation of the gestures that constitute beginnings and endings can seem to shift as a song segment unfolds, thereby throwing into question the relationship of that riff to the boundaries of its segment. Developing a rhythmic understanding of these moments-indeed the very recognition that a reorientation is taking place - depends on the temporality of listening. Without listening, the lurches and reorganizations that comprise a key element of Meshuggah's style lose their vitality, and the reason that fans hurl their bodies against each other in the mosh pit grows obscure.

[54] In his study on rhythm in electronic dance music, Mark Butler finds that:

Metrically ambiguous sections encourage the listener to construe the meter actively rather than absorb metrical information passively. On the dance floor, this construction occurs in and between bodies as well as in minds. (2006, 137)

When listeners tune in to the rhythmic patterns of Meshuggah's music, or hurl their bodies about the floor in front of the stage, they likewise demonstrate the combination of physical and mental energy that makes a Meshuggah concert such an arresting experience for fans. Further, Vijay Iyer finds that: 
Music perception and cognition are embodied activities, depending crucially on the tangible features of our sensorimotor apparatus, and also on the sociocultural environment in which music perception, cognition, and production are situated. $(1998,137)$

Rhythmic understanding, therefore, is both embodied and culture-specific. Iyer also observes that according to neuropsychological data, the mental processes that produce physical movement are the same as those involved in listening to music (30-31). The listeners who appear to be primarily absorbed in the intensely physical process of moshing, are additionally necessarily involved in music cognition, in a sociocultural situation that encourages a distinctly violent mode of musical participation-one that enacts freedom from specific social norms within the control of the musical event.

[55] The listeners preferring to count are, for their own part, more physically engaged than it would appear. From the perspective of those who explicitly prefer numbers, Jeanne Bamberger and Andrea diSessa (2003) have explored "music as embodied mathematics," in an effort to empirically support Leibniz' assertion that "Music is a secret arithmetic exercise in which the soul is not aware that it is counting."(25) The affinity between music and math is a longstanding one, though not typically associated with attendance at extreme metal concerts. The "nerds" in the balcony use embodied cognition of the music for the pleasure of processing the rhythmic patterns as they go by, while preferring to keep the motion in their minds; they and the moshers share more of the concert experience than meets the eye. The moshers count implicitly with their bodies, while the "nerds" count explicitly with the aid of embodied musical knowledge and habits. They offer differing surface animations of similar internal activities: engagement with sound.

[56] In meditating on the nature of beginnings in music (and in human activities more broadly), Lydia Goehr writes:

Many insist that a beginning must make sense, for if it doesn't, there's little inclination to pursue matters further. The beginning must grab us, put us in the right mood. Yet if getting in the mood presupposes a preparation, shouldn't the preparation count as a part of the beginning, or even be reckoned as the real beginning itself? $(2015,[2])$

The beginnings of three of the riffs analyzed above are unclear, foggy, and deceptive. The song segments begin, and then begin again retrospectively as the groupings sort themselves into their most rhythmically coherent forms. Just as the moshers began their dance "before the beginning," as a prelude that prepared the entrance of the band, so do these riffs begin before their own beginnings, thereby preparing endings that play with a formal norm of the band's style. In answer to Goehr's query of, "Does it matter where we begin?" obZen seems to suggest that it matters a great deal, as it profoundly impacts where and how we end.

Olivia R. Lucas

New Zealand School of Music | Te Kōkī

Victoria University of Wellington

Wellington 6012

New Zealand

olivia.lucas@vuw.ac.nz

\section{Works Cited}

Agawu, Kofi V. 1991. Playing with Signs: A Semiotic Interpretation of Classical Music. Princeton University Press.

Angle, Brad. 2013. “Interview: Meshuggah Discuss Their New Album, Koloss." Guitar World. http://www.guitarworld.com/features-interviews-gear-galleries/interview-meshuggah-discusstheir-new-album-koloss. 
Bamberger, Jean and Andrea diSessa. 2003. "Music as Embodied Mathematics: A Study of a Mutually Informing Affinity." International Journal of Computers for Mathematical Learning 8 (2): 123-160.

Biamonte, Nicole. 2014. "Formal Functions of Metric Dissonance in Rock Music." Music Theory Online 20 (2). http://www.mtosmt.org/issues/mto.14.20.2/mto.14.20.2.biamonte.html

Björler, Anders and Owe Lingvall, directors. 2012. Konstrukting the Koloss. DVD. Nuclear Blast.

Blabbermouth. 2008. "Meshuggah Guitarist on Songwriting Process, 'Math Metal' Tag." Blabbermouth. http://www.blabbermouth.net/news/meshuggah-guitarist-on-songwriting-process-math-metal$\operatorname{tag} /$.

Bregman, Albert S. 1990. Auditory Scene Analysis: The Perceptual Organization of Sound. MIT Press.

Butler, Mark. 2006. Unlocking the Groove: Rhythm, Meter and Musical Design in Electronic Dance Music. Indiana University Press.

Caplin, William E. 1998. Classical Form: A Theory of Formal Functions for the Instrumental Music of Haydn, Mozart and Beethoven. Oxford University Press.

Caplin, William E. and James Hepokoski and James Webster. 2009. Musical Form, Forms and Formenlehre: Three Methodological Reflections. Ed. Pieter Bergé. Leuven University Press.

Capuzzo, Guy. 2014. "A Beat-Class Approach to Polyrhythm in the Music of Meshuggah." Paper presented at the annual meeting for the Society for Music Theory, Milwaukee, Wisconsin.

2018. "Rhythmic Deviance in the Music of Meshuggah." Music Theory Spectrum 40 (1): $121-137$.

Goehr, Lydia. 2015. “Does It Matter Where We Begin? Or, On the Art of Preparation and Preluding." Music Theory Online 21 (3).http://www.mtosmt.org/issues/mto.15.21.3/mto.15.21.3.goehr.html

Hasty, Christopher. 1997. Meter as Rhythm. Oxford University Press.

Iyer, Vijay. 1998. "Microstructures of Feel, Macrostructures of Sound: Embodied Cognition in West African and African-American Musics." PhD diss., University of California, Berkeley.

Krebs, Harald. 1999. Fantasy Pieces: Metrical Dissonance in the Music of Robert Schumann. Oxford University Press.

Levy, Janet. 1981. "Gesture, Form and Syntax in Haydn's Music.” In Haydn Studies: Proceedings of the International Haydn Conference, ed. Jens Peter Larsen, Howard Serwer and James Webster, 355-363. W. W. Norton and Company.

Lidov, David. 2005. Is Language a Music? Writings on Musical Form and Signification. Indiana University Press.

Lokhorst, Gert-Jan. 2015. "Descartes and the Pineal Gland." In The Stanford Encyclopedia of Philosophy. Ed. Edward N. Zalta. Stanford University. http://plato.stanford.edu/archives/fall2015/entries/pineal-gland/.

McFarland, Ian, director. 2010. Alive. DVD. Nuclear Blast.

Meshuggah. 2012. "Web Chat with Tomas Haake and Jens Kidman." Nuclear Blast. https://www.youtube.com/watch?v=Ry1Mm1q_FBg.

O'Neill, Christina. 2016. “Meshuggah Recorded Violent Sleep of Reason Live.” Team Rock. http://teamrock.com/news/2016-08-19/meshuggah-recorded-violent-sleep-of-reason-live.

Osborn, Brad. 2011. "Understanding Through-Composition in Post-Rock, Math-Metal, and other Post-Millennial Rock Genres." Music Theory Online 17 (3). http://www.mtosmt.org/issues/mto.11.17.3/mto.11.17.3.osborn.html 
Pieslak, Jonathan. 2007. "Re-Casting Metal: Rhythm and Meter in the Music of Meshuggah." Music Theory Spectrum 29 (2): 219-245.

Previ, Dave. 2013. “Web Exclusive Interview with Meshuggah's Tomas Haake.” Modern Drummer. http://www.moderndrummer.com/site/2013/06/web-exclusive-interview-with-meshuggahs-tomashaake/\#.VRu5CkbXV19.

Radio Fortuna. 2008. “Interview with Tomas Haake.” Drumtalk. https://www.youtube.com/watch? $\mathrm{v}=$ Mazw9sFapuM\&feature=related.

Scherzinger, Martin. 2010. "Temporal Geometries of an African Music: A Preliminary Sketch." Music Theory Online 16 (4). http://www.mtosmt.org/issues/mto.10.16.4/mto.10.16.4.scherzinger.html

Smialek, Eric. 2008. "Rethinking Metal Aesthetics: Complexity, Authenticity, and Audience in Meshuggah's I and Catch Thirtythr33." Masters thesis, McGill University.

Straus, Joseph N. 2006. "Normalizing the Abnormal: Disability in Music and Music Theory." Journal of the American Musicological Society 59 (1): 113-184.

Walser, Robert. 1993. Running with the Devil: Power, Gender and Madness in Heavy Metal Music. Wesleyan University.

Weiss, David. 2010. “Tomas Haake: Meshuggah Goes It Alone.” Drum!

http://www.drummagazine.com/features/post/tomas-haake-meshuggah-goes-it-alone/.

Wincent Drumsticks AB. 2015. “Tomas Haake Studio Report." Wincent Drumsticks AB. https://www.youtube.com/watch?v=hYjjwL022-0.

Zbikowski, Lawrence M. 2004. "Modelling the Groove: Conceptual Structure and Popular Music." Journal of the Royal Music Association 129 (2): 272-297.

\section{Footnotes}

* I would like to thank the colleagues and anonymous reviewers whose comments helped improve this article, an earlier version of which was presented at the 2017 meeting of the Society for Music Theory.

Return to text

1. As is typical of extreme metal performance practice, Meshuggah's live performances tend to faithfully reproduce their recordings. Occasional discrepancies do emerge, however, and I discuss some of these later. Meshuggah's members have repeatedly demonstrated themselves capable of performing their music with near-mechanical accuracy in live settings, and they have furthermore admitted that achieving this level of performance requires a great deal of practice. Due to the difficulty of performing their music live, songs for a tour's setlist are decided well in advance to allow for sufficient rehearsal time; for example, "Bleed" (obZen) allegedly took drummer Tomas Haake over six months of practice to be able to play through continuously (Weiss 2010). The band has also admitted that there are some songs that will likely never receive a live performancesongs like "The Demon's Name is Surveillance" (from 2012's Koloss) - as they have not been able to get to a point where they can perform them without physical discomfort (Previ 2013). Similarly, they say they will never perform the twenty-minute single-track EP I (2004), with Haake describing the song's form as "random" and saying "no one [in the band] knows how I goes" (McFarland 2010). (For an analysis of portions of $I$, see Pieslak 2007, 223-42.)

Technology plays a significant role in Meshuggah's compositional process, as programming has replaced the demo in their songwriting process. The challenge, then, is that they can program anything, but they "need to be able to play it as well"; Haake adds that the temptation in programming is for the mind to outstrip the body's ability, and that he resists this temptation by trying to "feel" his way through the programming process (Wincent Drumsticks AB 2015). While tempo is usually dealt with during recording, they have occasionally shown flexibility with regard to performance tempi. Live performances of the title song "obZen," for example, are slower than 
the recorded version by about $10 \mathrm{bpm}$, allowing the song's groove to "breathe" a bit more. Most recently, they have placed a renewed emphasis on live performance in their recording process, as the 2016 album The Violent Sleep of Reason was recorded live. This process enabled them to avoid the issues of tempo and playability that arose when learning material from obZen and Koloss for touring purposes, and in Haake's opinion resulted in a more "honest" sound (O'Neill 2016).

Music technology has pushed Meshuggah toward discovering their limits as human performers. Nevertheless, they remain committed to producing songs that by and large work in a live setting. That they give an impression of "sonic machines" during performances has not only to do with the role they allow technology to play in their compositional process, but also the meticulously synced lightshow, the lack of banter or excessive movement on stage, and Kidman's robotic and deliberately "monotonous" vocals, which together form the band's carefully cultivated performance style (Radio Fortuna 2008).

Return to text

2. The band has been assigned many genres, including extreme metal, death metal, progressive metal, math metal and experimental metal. For simplicity, I refer to their genre here as "extreme metal," an umbrella term that encompasses a wide variety of subgenres characterized by sonic, visual, and lyrical transgressiveness. For an analysis of Meshuggah's participation in genre(s), see Smialek 2008.

Return to text

3. The name of the band was not chosen to signal any particular connection to or reflection on Judaism or Jewishness. Jonathan Pieslak notes that the band claims they chose it because it "sounds $\operatorname{cool}^{\prime \prime}(2007,219)$.

Return to text

4. Meshuggah have not been without their detractors. Criticism of their music has focused on the lack of melody and lack of textural variation, elements which fans often praise. They are also thought to have spawned the "djent" sub-genre, which takes Meshuggah's stylized, processed, and palm-muted guitar tone (for which the sub-genre is onomatopoetically named) and incorporates it into more melodic styles of metal music, often with heavy use of electronics.

Return to text

5. In their 2012 album Koloss, the band begins to weaken the edges of this ${ }_{4}^{4}$ based hyperstructure, allowing riffs to spill over the edges of their song segments, and playing with the looping of riffs within each song segment, modifying them to create subtle motivic variations. See, for example, the songs "Do Not Look Down" (0:00-1:48; analyzed in Capuzzo 2014 and 2018), "Break Those Bones Whose Sinews Gave It Motion" (0:27-1:23), and "Swarm" (0:52-1:36).

Return to text

6. Meshuggah sometimes uses a technique in which the last repetition of a riff within a given segment is altered and rhythmically shortened or lengthened to bring it back into alignment with the hypermetrical structure. See, for example, Pieslak's 2007 analysis of "Rational Gaze" (222).

Pieslak does not make a distinction between riffs that are altered to bring them into alignment and those that are cut off mid-stride; for him, all riffs end with an altered version, even if the alteration is only a truncation of the original. Capuzzo (2018) refers to these lengthened, truncated, or altered final repetitions as "tails"; he also does not distinguish between alteration of the pattern itself and cutting it off before it's finished (123). For Capuzzo, a riff with no tail is one which is not cut off and therefore runs over the boundaries of the song segment $(2018,132)$. The examples presented here happen to exclusively feature riffs that are cut off mid-stride at the end of the song segment. Since my analyses here are largely concerned with felt qualities of "beginning" and "ending," I feel that this distinction between a rhythmic pattern that is cut short versus one in which the internal pitches and/or rhythms are altered so as to re-align with the hypermetrical structure is important and deserves additional future research in its own right.

Return to text 
7. Here, I follow Krebs in understanding meter as "the union of all layers of motion (i.e. series of regularly recurring pulses) active [in the music]" $(1999,23)$. Following Biamonte, rhythmic dissonances "do not normally disrupt the meter (Krebs's "submetrical dissonances"; 1999, 30), occur at the tactus level-in ${ }_{4}^{4}$, the quarter-note beat-and below. . Metric dissonances disrupt the bar and the conducting pattern" (2014, [1.3]).

Return to text

8. One question that arises frequently is how the band members themselves understand rhythm in their music. Historically, they have been reluctant to discuss the use of rhythm and meter in their music in detail. (Of the five current members, only the bassist (Dick Lövgren) is formally trained in music, having studied jazz at the University of Gothenburg.) When asked, they tend to state simply that everything is conceived in ${ }_{4}^{4}$, and that is how they hear and count it (Weiss 2010, among others). Drummer Tomas Haake has stated that the band learns the music in "chunks" of four, eight, or sixteen measures of ${ }_{4}^{4}$, supporting the strong form-generating role that these song segments have (Meshuggah 2012). The band's rhythm guitarist, Mårten Hagström, however, has also emphasized the importance of groove to their compositional approach, comparing their music to funk (Blabbermouth 2008) and saying, "Sometimes people think we set out to create these crazy patterns and then make them work. That's not how it works. . You just have to find the groove and then work with the weird stuff until it makes sense" (Angle 2013). Focusing on groove takes some of the emphasis off abstraction and complexity, and instead underlines the role that intuition and "feeling" play in the band's composing, rehearsing, and performing of this music, and in audience enjoyment of it. "Groove" is, of course, a notoriously slippery musical concept; here, Lawrence Zbikowski's understanding of groove as a kind of embodied musical knowledge associated with physical movement is particularly useful (2004, 272-297). In the context of the Meshuggah concert described in the opening of this article, both the moshers and the "nerds" in the balcony were searching for the groove-one visibly emphasizing the physical aspects of participation, and the other, the mental, but both experiencing embodied and cognitive musical engagement. The band's tendency to downplay the complexity of their music not only performs a nonchalant, rock-is-fromthe-heart attitude and reassures fans that they need not be theory experts to enjoy the music, but also reminds us of the role of rhythmic instinct as embodied group knowledge in their compositional style. That they are admired by both those who wish to count each rhythmic stream as it goes by as well as by those who would prefer to slam their bodies against one another gives credence to both perspectives.

Return to text

9. Mark Butler also explicitly brings together Krebs's understanding of meter and metric and rhythmic dissonance with a Hasty-inspired approach to rhythmic analysis in his study of electronic dance music (2006, 100-111).

Return to text

10. Meshuggah's riffs often employ octatonic, whole tone, and chromatic pitch collections (Capuzzo 2018, 127). A detailed study of pitch in Meshuggah's music is beyond the scope of this article.

Return to text

11. Some songs having at least one riff in which "ending" is indicated by a durational accent include: "Stengah" (0:16-0:46) from Nothing (2002); “Electric Red" (1:10-1:44), “Lethargica” (0:000:36), "Pineal Gland Optics" (0:00-0:40), and "Pravus" (2:31-3:00) from obZen (2008); and "Marrow" (0:00-0:36) from Koloss (2012).

Return to text

12. Some songs having at least one riff shaped primarily by contour or registral accents include: "Bleed" (0:00-0:16, 6:27-6:45) and "Pravus" (0:00-1:11) from obZen (2008); and "The Demon's Name is Surveillance" (0:00-0:26) and "Swarm" (0:00-2:04) from Koloss (2012).

Return to text

13. Though my analyses focus on the formation and communication of "beginningness," "middleness," and "endness," I wish to distinguish my approach from semiotic and Formenlehre 
approaches that have focused on this process of signification in the context of tonal music. Most notably, William Caplin's $(1998,2009)$ notion of formal functions and semiotic studies of tonal music - e.g. those of Kofi Agawu (1991) and David Lidov (2005) - have both concerned themselves with how different kinds of musical patterns communicate "beginningness," "middleness" or "endness," to the extent that acculturated listeners can arrive late to the symphony and reliably tell where in the movement they are, based solely on the sounds they hear. The establishment of such strong semiotic norms meant that composers such as Haydn could "joke" with audiences, for instance by beginning with a cadential gesture that strongly evoked "ending" (See: Levy 1981, 355-363). Euroclassical music is unique in its development of strong conventions for indicating beginnings, middles and endings, to the point where listeners have forgotten that there is nothing intrinsic to the sound of a cadence that necessarily says "ending." While my analyses do investigate the form-generating role of beginnings, middles and endings in Meshuggah's music, they occur outside of tonality's cultural frame; Meshuggah's music enacts neither local nor large-scale tonal processes. As there are no background tonal processes, the analyses remain local and tied to the musical gesture in progress.

Return to text

14. For the sake of visual simplicity, guitar transcriptions represent both the rhythm and bass guitar, which typically play an octave apart. Meshuggah uses down-tuned eight-string guitars (most common tuning: $\mathrm{F}, \mathrm{B} b, \mathrm{E} b, \mathrm{~A} b, \mathrm{D} b, \mathrm{G} b, \mathrm{~B} b, \mathrm{E} b$ ), and five-string basses (most common tuning: $\mathrm{B} b, \mathrm{~F}, \mathrm{~B} b, \mathrm{E} b, \mathrm{~A} b$ ). All transcriptions are mine. I generally omit ornaments and articulation marks (slides, bends, palm muting, etc.) to prevent clutter; these transcriptions are meant as a visual aid to understanding certain rhythmic processes, rather than as a set of instructions that would allow a player to faithfully imitate every aspect of the recording (i.e., they are descriptive, rather than prescriptive).

Return to text

15. I imagine that for someone learning to play this riff, developing some sense of an attack point pattern would be useful. Here, counting sixteenth notes, the attacks could be grouped 122, 212, 122, 123,12 , which could then be paired with the pitch pattern.

Return to text

16. N.B.: Haake uses multiple cymbals, but for the sake of simplicity, throughout this article I transcribe them as a single instrument. In general, in transcribing percussion parts, I strive to minimize the use of rests in the service of visual simplicity, even when the sound notated is an attack followed by rapid decay.

Return to text

17. The downward leap of an octave or 9 th taken by the $~ \neg$. further strengthens the gesture, giving it more "weightiness."

Return to text

18. Though the f. figure that sounds in the beginning of $\mathrm{m}$. 17 seems as if it will re-start the same riff, the rhythmic and pitch patterns do change here, though they are certainly based on the initial riff. The 8-bar verse from mm. 17-24 descends half a step in both voices, hovering around $\mathrm{Ab}$ and $\mathrm{Gb}$. The rhythmic pattern in these eight measures contains elements of mm. 1-16's $6 \cdot$ riff, as it remains a jagged leaping pattern and makes use of the $\sqsubset, \Gamma$. and $\Gamma$ rhythmic elements of the first pattern. There is no set pattern in this verse; it divides into groupings (using $\sqrt{ }$. to mark

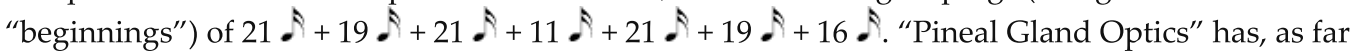
as I can tell, never been performed live by the band. This may be due in part to the difficulties presented by the many conflicting rhythmic processes presented in the various layers. While slower in tempo than many songs, the guitar parts could present memorization difficulties, given the use of complicated isorhythms, the fact that all the riffs are derived from the opening one but none are exactly the same, and that the verse patterns (during vocals) are irregular variations on the opening riff that never quite settle into a repeating riff. Furthermore, the use of patterns that sound as if they begin in the middle, as analyzed here, adds an additional layer of complication from a performance perspective. Though "Pravus" (analyzed below) also makes use of this technique, its context is generally more straightforward, particularly as the drum and cymbal 
patterns forthrightly support the patterns being performed in the guitar.

Return to text

19. Evidence from auditory scene analysis - the study of how the brain segments or "streams" auditory information - may prove useful in showing how the elements of this riff cohere. While the laboratory experiments involved in auditory scene analysis generally use isolated series of tones, rather than complete musical contexts, Albert Bregman has argued that music relies on the properties of primitive auditory processes to achieve its effects, and that these processes work the same way in the laboratory and the wider world $(1990,528)$. With regard to the riff shown in Examples 14-19, experimental evidence suggests that tones closer together in time tend to be grouped together mentally, as well as those close in pitch (52). The circled notes in Example 14 are only a semitone apart, while the other pitches are a 6th or more lower, in addition to sounding softer, causing the upper As and G\#s to hang together in a coherent "stream."

Return to text

20. There are some discrepancies with regard to performance of this lead guitar part. In the album version of the song, the lead guitar in this passage is mixed well to the back, to the extent that it has a hazy "background" effect compared to the structuring role of the lead guitar oscillation in "Pineal Gland Optics." In live renditions of "Pravus," however, the lead guitar is more clearly audible, and the pitch changes occur strictly every eight beats. As in "Pineal Gland Optics," I have chosen to transcribe the lead guitar as I hear it on the album version, for consistency with my other examples. Return to text

21. This rhythmic "blending" effect also occurs in "Bleed," though it is used to confuse repetitions of a $9 .+9+6$ riff within the song section, rather than the borders between song sections. See “Bleed," 3:37-4:13.

Return to text

22. Osborn (2011, [36]) finds that ". . .math metal bands [a category in which he includes Meshuggah] tend to build compositions by concatenation of thematically diverse guitar riffs." His analyses of songs by The Dillinger Escape Plan and The Chariot further suggest that, "the focus seems to be on presenting the most interesting, groovy, and technically demanding riffs one can muster, rather than on creating any sort of thematically unified piece" ([23]). On the surface, $o b Z e n$ 's style seems to bear out this "concatenation of. . .riffs" hypothesis, as the rhythmic patterns continue to shift with each passing song segment. But the hypermetrical regularity of those passing segments provides a systematic structural undergirding to this highly differentiated rhythmic surface that is absent in the examples Osborn analyzes.

Return to text

23. Meshuggah's lyrics are written by Tomas Haake, the band's drummer. Haake also writes the rhythms for the vocal parts (Björler and Lingvall 2012).

Return to text

24. Here, I draw on Straus' identification of metaphors based in embodied experiences of ability and disability that frequently arise in analytical literature, such as "balance/imbalance" and "container" (123).

Return to text

25. "Musica est exercitium arithmeticae occultum nescendis se numerare animi." From a 1712 letter to Christian Goldbach.

Return to text

\section{Copyright Statement}

Copyright $\odot 2018$ by the Society for Music Theory. All rights reserved.

[1] Copyrights for individual items published in Music Theory Online (MTO) are held by their authors. Items appearing in MTO may be saved and stored in electronic or paper form, and may be shared among individuals for purposes of scholarly 
research or discussion, but may not be republished in any form, electronic or print, without prior, written permission from the author(s), and advance notification of the editors of MTO.

[2] Any redistributed form of items published in MTO must include the following information in a form appropriate to the medium in which the items are to appear:

This item appeared in Music Theory Online in [VOLUME \#, ISSUE \#] on [DAY/MONTH/YEAR]. It was authored by [FULL NAME, EMAIL ADDRESS], with whose written permission it is reprinted here.

[3] Libraries may archive issues of MTO in electronic or paper form for public access so long as each issue is stored in its entirety, and no access fee is charged. Exceptions to these requirements must be approved in writing by the editors of $M T O$, who will act in accordance with the decisions of the Society for Music Theory.

This document and all portions thereof are protected by U.S. and international copyright laws. Material contained herein may be copied and/or distributed for research purposes only. 